\title{
High Curie Temperature BiFe03-BaTi03 Lead-free Piezoelectric Ceramics: Ga3+ Doping and Enhanced Insulation Properties
}

\section{Xiao-yan Peng}

University of Science and Technology Beijing

\section{Yu-Cheng Tang}

University of Science and Technology Beijing

\section{Boping Zhang ( $\nabla$ sendaimr@foxmail.com )}

Beijing Key Laboratory of New Energy Materials and Technology, School of Materials Science and Engineering, University of Science and Technology Beijing, Beijing 100083, P.R. China https://orcid.org/0000-0003-1712-6868

\section{Bo-wei Xun}

University of Science and Technology Beijing

Jing-Ru Yu

University of Science and Technology Bejing

\section{Research Article}

Keywords: BiFeO3-BaTiO3, High Curie temperature, Leakage mechanism, Piezoelectric

Posted Date: October 30th, 2020

DOl: https://doi.org/10.21203/rs.3.rs-98834/v1

License: @ (i) This work is licensed under a Creative Commons Attribution 4.0 International License. Read Full License 


\title{
High Curie temperature $\mathrm{BiFeO}_{3}-\mathrm{BaTiO}_{3}$ lead-free piezoelectric ceramics: $\mathrm{Ga}^{3+}$ doping and enhanced insulation properties
}

\author{
Xiao-yan Peng ${ }^{\mathrm{a}, \mathrm{b}, 1}$, Yu-cheng Tang ${ }^{\mathrm{a}, 1}$, Bo-ping Zhang ${ }^{\mathrm{a},}{ }^{*}$, Bo-wei Xun ${ }^{\mathrm{a}}$, Jing-ru Yu ${ }^{\mathrm{a}}$ \\ a Beijing Key Laboratory of New Energy Materials and Technology, School of Materials Science and Engineering, \\ University of Science and Technology Beijing, Beijing 100083, P.R. China \\ b Beijing Key Laboratory of Special Ceramics and Refractories, New Metallurgy Hi-Tech Group Co., Ltd. , China Iron \\ \& Steel Research Institute Group, Beijing 100081, P.R. China \\ ${ }^{1}$ Xiao-yan Peng and Yu-cheng Tang equally contributed to this work. \\ *Corresponding Author: bpzhang@ustb.edu.cn
}

\begin{abstract}
$\mathrm{BiFeO}_{3}-\mathrm{BaTiO}_{3}(\mathrm{BF}-\mathrm{BT})$ is a promising high temperature lead-free piezoceramics due to their excellent piezoelectric properties with high Curie temperature $\left(T_{\mathrm{C}}>500{ }^{\circ} \mathrm{C}\right)$. While the high leakage current density severely restricted its application. In this work, the leakage mechanism relative to the dielectric properties and piezoelectric properties were systematically studied with a special emphasis on gallium $\left(\mathrm{Ga}^{3+}\right)$ adding effect in $0.7 \mathrm{BiFe}_{(1-x)} \mathrm{Ga}_{x} \mathrm{O}_{3}-0.3 \mathrm{BaTiO}_{3}(\mathrm{BFGax}$-BT, $0 \leq x \leq 0.10)$ ceramics. A high resistivity $(\rho)$ of $2.73 \times 10^{12}$ $\Omega \cdot \mathrm{cm}^{-1}$ and low leakage current $(J)$ of $7.78 \times 10^{-9} \mathrm{~A} \cdot \mathrm{cm}^{-2}$ were achieved at $x=0.06$, which attributes to the low oxygen vacancies $\left(\mathrm{V}_{\mathrm{O}}^{\bullet \bullet}\right)$. The $J-E$ curves reveal different type of conduction process in BFGax-BT ceramics, including Ohmic conduction, space-charge-limited conduction (SCLC) mechanism and interface-limited Schottky emission. The BFGa0.06-BT ceramic exhibits excellent piezoelectric performance: $d_{33}=174 \mathrm{pC} \cdot \mathrm{N}^{-1}$, $T_{\mathrm{C}}=497{ }^{\circ} \mathrm{C}, k_{\mathrm{p}}=29 \%$.
\end{abstract}

Keywords: $\mathrm{BiFeO}_{3}-\mathrm{BaTiO}_{3}$, High Curie temperature, Leakage mechanism, Piezoelectric

\footnotetext{
*Corresponding author. Tel.: +86-010-62334195. E-mail address: bpzhang@ustb.edu.cn (B.-P. Zhang)
} 


\section{Introduction}

Lead-based $\mathrm{Pb}(\mathrm{Ti}, \mathrm{Zr}) \mathrm{O}_{3}$ (PZT) ceramics are primary commercial piezoelectric ceramics and widely used in sensors, brakes and transducers[1]. However, the application of lead-based piezoelectric ceramics is restricted by the toxicity of lead, which promotes the development of lead-free piezoelectric ceramics, such as $\mathrm{BiFeO}_{3}$ (BF) [2-4], $\mathrm{BaTiO}_{3}$ (BT) [5-6], $\mathrm{K}_{1 / 2} \mathrm{Na}_{1 / 2} \mathrm{NbO}_{3}$ (KNN) [7-9], $\mathrm{Bi}_{1 / 2} \mathrm{Na}_{1 / 2} \mathrm{TiO}_{3}$ (BNT) [10-11]. Among them, BF is a promising lead-free piezoelectric ceramic due to the large spontaneous polarization of $88-100 \mu \mathrm{C} \cdot \mathrm{cm}^{-2}$ and high Curie temperature $\left(T_{\mathrm{C}}\right)$ of $836^{\circ} \mathrm{C}[2,4]$. A continuous $(1-x) \mathrm{BF}-x \mathrm{BT}$ solid solution with rhombohedral $(R)$, pseudocubic $(P C)$, and tetragonal $(T)$ symmetries was formed at $0.00 \leq x \leq 0.33$, $0.33 \leq x \leq 0.92$ and $0.92 \leq x \leq 1[12]$, respectively, which reveals the potential of both superior piezoelectricity and a high $T_{\mathrm{C}}$ in BF-BT system near the morphotropic phase boundary (MPB). Excellent $d_{33}(130-240$ $\left.\mathrm{pC} \cdot \mathrm{N}^{-1}\right)$ and large electric field-induced ( $E$-induced) strains $(S=0.2-0.3 \%)$ with high $T_{\mathrm{C}}\left(430-600{ }^{\circ} \mathrm{C}\right)$ were achieved in $(1-x)$ BF- $x$ BT ceramics at the MPB compositions of $0.25 \leq x \leq 0.35$ [13-16].

However, the narrow synthesis temperature range and $\mathrm{Bi}$ volatilization during solid-state reaction produce the formation of $\mathrm{Bi}_{25} \mathrm{FeO}_{40}$ and $\mathrm{Bi}_{2} \mathrm{Fe}_{4} \mathrm{O}_{9}$ phases and are obstacles for preparing pure (1- $\left.x\right) \mathrm{BF}-x \mathrm{BT}$ phase [16-18]. Besides, part of $\mathrm{Fe}^{3+}$ will transform into $\mathrm{Fe}^{2+}$ during calcining and sintering process. These factors all lead to the generation of a large amount of oxygen vacancies $\left(\mathrm{V}_{\mathrm{O}}^{\bullet \bullet}\right)$, resulting in a high leakage current $(J)$ and a large dielectric loss, which is harmful for polarization and obtaining saturated $P-E$ hysteresis loop [19-20]. Lots of attempts on reducing $J$ and enhancing direct current resistivity $(\rho)$ have been performed by optimizing preparation process and doping modification. Lee et al. inhibited the formation of secondary $\mathrm{Bi}_{2} \mathrm{Fe}_{4} \mathrm{O}_{9}$ and/or $\mathrm{Bi}_{25} \mathrm{FeO}_{39}$ phases by water quenching method, whereby a low leakage current density of $7.5 \times 10^{-10} \mathrm{~A} \cdot \mathrm{cm}^{-2}$ and an excellent piezoelectric property of $d_{33}=240 \mathrm{pC} \cdot \mathrm{N}^{-1}$ achieved in 0.67BF-0.33BT ceramics [21]. Using nano- $\mathrm{BaTiO}_{3} / \mathrm{Bi}_{2} \mathrm{O}_{3} / \mathrm{Fe}_{2} \mathrm{O}_{3}$ as raw materials instead of 
$\mathrm{BaCO}_{3} / \mathrm{TiO}_{2} / \mathrm{Bi}_{2} \mathrm{O}_{3} / \mathrm{Fe}_{2} \mathrm{O}_{3}$ to prepare $\mathrm{BF}-\mathrm{BT}$ ceramics, Cheng et al. realized an increased $d_{33}=210 \mathrm{pC} \cdot \mathrm{N}^{-1}$ from $164 \mathrm{pC} \cdot \mathrm{N}^{-1}$ in $0.7 \mathrm{BF}-0.3 \mathrm{BT}$ along with an order of magnitude improved insulation resistance [22]. Besides, the use of stability elements, like $\mathrm{La}, \mathrm{Ga}, \mathrm{Bi}\left(\mathrm{Zn}_{1 / 2} \mathrm{Ti}_{1 / 2}\right) \mathrm{O}_{3}$ and $\mathrm{Nd}$ etc., to replace $\mathrm{A}$ and/or $\mathrm{B}$ site of $\mathrm{BF}$ is also effective to enhance the electrical performance of $(1-x) \mathrm{BF}-x \mathrm{BT}$ ceramics [23-26]. It is reported that the water quenched $\mathrm{BF}-33 \mathrm{BT}-3 \mathrm{BiGaO}_{3}$ ceramic exhibited excellent piezoelectric properties $d_{33}=402$ $\mathrm{pC} \cdot \mathrm{N}^{-1}$ with high $T_{\mathrm{C}}=454{ }^{\circ} \mathrm{C}$, which attributes to the low $J=1 \times 10^{-10} \mathrm{~A} \cdot \mathrm{cm}^{-2}$ under the electric field of 50 $\mathrm{kV} \cdot \mathrm{cm}^{-1}[21]$. However, the water quenching process is difficult to commercialize for its poor repeatability. It is necessary to prepare excellent performance Ga-doped BF-BT using traditional methods. Zhou et al. realized good piezoelectric properties: $d_{33}=157 \quad \mathrm{pC} \cdot \mathrm{N}^{-1}, \quad k_{\mathrm{p}}=0.326, \quad$ and $\quad T_{\mathrm{C}}=464 \quad{ }^{\circ} \mathrm{C} \quad$ in $0.71 \mathrm{Bi}\left(\mathrm{Fe}_{1-x} \mathrm{Ga}_{x}\right) \mathrm{O}_{3}-0.29 \mathrm{BT}$ ceramics at $x=0.015$ [27]. But the leakage conduction mechanism of Ga-doped BF-BT ceramics is still unclear, and needs to investigate thoroughly. In this work, the $0.7 \mathrm{BiFe}_{(1-x)} \mathrm{Ga}_{x} \mathrm{O}_{3}-0.3 \mathrm{BaTiO}_{3}(\mathrm{BFGax}-\mathrm{BT}, 0 \leq x \leq 0.10)$ ceramics near the MPB were prepared by conventional solid sintering method, the leakage mechanism evolution, dielectric properties and piezoelectric properties were systematically studied. Benefitted to the suppressed valence of $\mathrm{Fe}^{3+}$ and $\mathrm{V}_{\mathrm{O} 1}^{\bullet \bullet}$ by Ga-doping, the BFGa0.06-BT ceramic exhibits excellent piezoelectric performance: $d_{33}=174 \mathrm{pC} \cdot \mathrm{N}^{-1}, T_{\mathrm{C}}=497{ }^{\circ} \mathrm{C}, k_{\mathrm{p}}=29 \%$, along with a high $\rho=2.73 \times 10^{12} \Omega \cdot \mathrm{cm}^{-1}$ and low $J=7.78 \times 10^{-9} \mathrm{~A} \cdot \mathrm{cm}^{-2}$.

\section{Experimental section}

The conventional solid-state reaction method was used to prepare the $0.7 \mathrm{BiFe}_{(1-x)} \mathrm{Ga}_{x} \mathrm{O}_{3}-0.3 \mathrm{BaTiO}_{3}$ $(0 \leq x \leq 0.10)$ (BFGax-BT) ceramics using $\mathrm{Fe}_{2} \mathrm{O}_{3}, \mathrm{Bi}_{2} \mathrm{O}_{3}$, (>99 \%, both from Shantou Xilong Chemical Factory Guangdong, China), nano-particle BT (>99.9 \%, from Aladdin, $C$-phase) and $\mathrm{Ga}_{2} \mathrm{O}_{3}(>99.99 \%$, from Aladdin). These raw materials were weighed according to the chemical formula, and then mixed thoroughly in ethanol for $24 \mathrm{~h}$ by using a planetary ball mill. After calcining the mixtures at $800{ }^{\circ} \mathrm{C}$ for $6 \mathrm{~h}$, the powders 
were re-milled, and then pressed into pellets of $10 \mathrm{~mm}$ in diameter and $1 \mathrm{~mm}$ in thickness under $80 \mathrm{MPa}$ with 2 wt\% polyvinyl alcohol (PVA). After excluding binder at $650{ }^{\circ} \mathrm{C}$ for $2 \mathrm{~h}$, the pressed pellets were sintered at $980^{\circ} \mathrm{C}$ for $3 \mathrm{~h}$ with the heating rate of $5^{\circ} \mathrm{C} \cdot \min ^{-1}$. The sintered specimens were pasted with silver on both surface and fired at $600{ }^{\circ} \mathrm{C}$ for $20 \mathrm{~min}$, then poled under a DC field of $3.5 \mathrm{kV}$ at $100{ }^{\circ} \mathrm{C}$ for $10 \mathrm{~min}$ in a silicone oil bath.

The X-ray diffraction (XRD) with $\mathrm{Cu} K_{\alpha}$ radiation (D/max-RB, Rigaku Inc., Japan) was used to examine crystalline structure of the sintered samples. Rietveld refinement was performed by using Materials studio software. The microstructure of the sintered samples was observed using field emission scanning electron microscopy (FESEM, SUPRATM 55, Japan). Bulk density was measured by using the Archimedes' method. The powders chemical state of the prepared ceramics was characterized by X-ray photoelectron spectroscopy (XPS: Thermo Fisher ESCALAB 250Xi) using Al $K_{\alpha}$ radiation $(h v=1486.6 \mathrm{eV})$ as an X-ray source. Dielectric properties were measured using a programmable furnace with a LCR analyzer (TH2828S) at $100 \mathrm{kHz}$ in temperature range of $25{ }^{\circ} \mathrm{C}$ to $600{ }^{\circ} \mathrm{C}$. The piezoelectric properties were measured using a quasi-static piezoelectric coefficient testing meter (ZJ-3A, Institute of Acoustics, Chinese Academy of science, Beijing, China). The $k_{\mathrm{p}}$ and the mechanical quality factor $\left(Q_{\mathrm{m}}\right)$ were determined by resonance-antiresonance method using an Agilent 4294A precision impedance analyzer (Hewlett-Packard, Palo Alto, CA). The $J$ and $\rho$ was measured by AT683 insulation test instrument (Applent instruments Ltd, China). A ferroelectric measuring equipment (aixACCT TF Analyzer 1000, Germany) was used to obtain the ferroelectric hysteresis $(P-E)$ loops and field-induced strain $(S-E)$ loops.

\section{Results and discussion}

Fig. 1a-b shows the $\rho-E$ and $J-E$ curves of poled BFGax-BT ceramics measured at room temperature (RT). The $\rho$ of all samples rapidly decreases with $E$ increasing at $E \leq 8 \mathrm{kV} \cdot \mathrm{cm}^{-1}$. When $E>8 \mathrm{kV} \cdot \mathrm{cm}^{-1}$, the $\rho$ of 
$0 \leq x \leq 0.02$ still decreases, while that of $0.04 \leq x \leq 0.1$ hold steady. The $\rho$ of $x=0.06$ is around $2.73 \times 10^{12} \Omega \cdot \mathrm{cm}^{-1}$ under $E=12 \mathrm{kV} \cdot \mathrm{cm}^{-1}$, which is larger than that of BF-BT $\left(0.55 \times 10^{12} \Omega \cdot \mathrm{cm}^{-1}\right)$, indicating an effectively enhanced the insulation of BF-BT ceramics via Ga-doping. The $J$ of BFGax-BT ceramics shows a different trend, which increases with $E$ increasing.

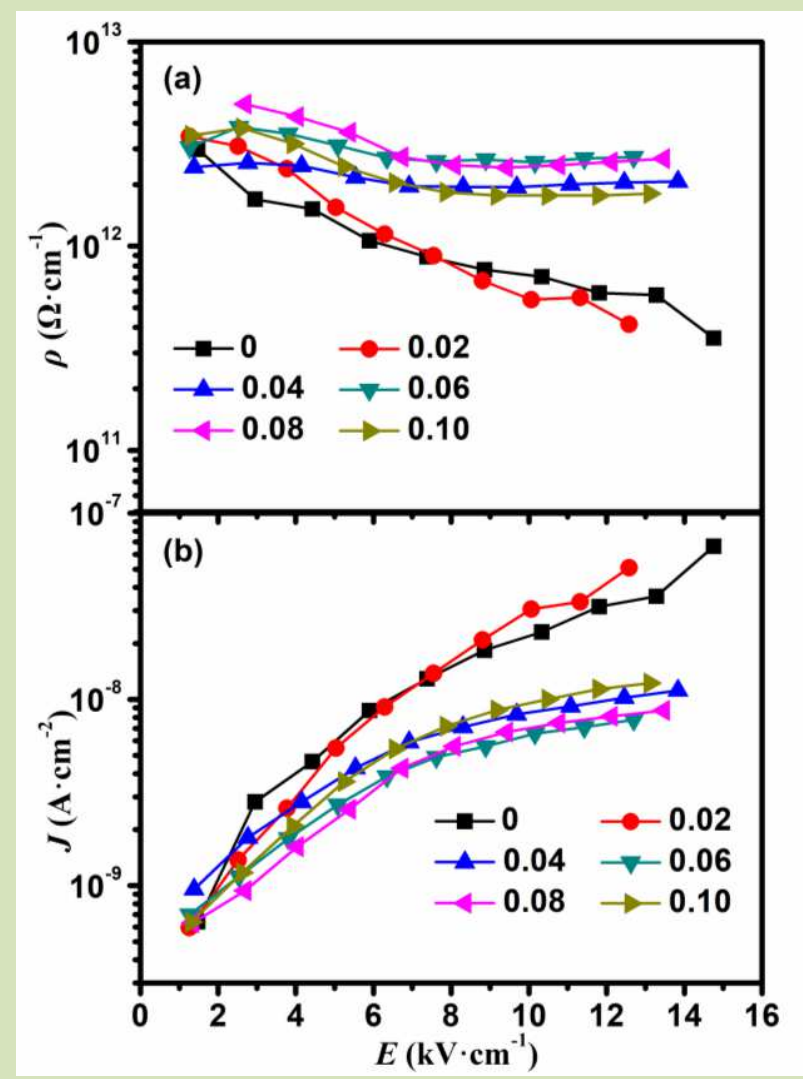

Fig. $1 \rho-E\left(\right.$ a) and $J-E\left(\right.$ b) of $\mathrm{BFGa}_{x}$-BT ceramics measured at room temperature.

According to the previous reported transport behavior of $\mathrm{BiFeO}_{3}$ and other similar ferroelectric perovskite oxides [20,28-32], the relationship between the leakage current $(J)$ and the applied electric field (E) for Ohmic conduction, space-charge-limited conduction (SCLC) mechanism and interface-limited Schottky emission are expressed as in Eq. (1-3) as follow:

$$
J_{\text {Ohmic }}=e \mu N_{e} E
$$

Where $e$ is the electron charge, $\mu$ is the free carrier mobility, $N_{e}$ is the density of the thermally stimulated electrons.

$$
J_{\mathrm{SCLC}}=\frac{9}{8} \varepsilon_{\mathrm{r}} \varepsilon_{0} \mu \theta \frac{E^{2}}{d}
$$


Where $\varepsilon_{\mathrm{r}}$ is the static dielectric constant, $\varepsilon_{0}$ is the permittivity of free space, $\mu$ is the free carrier mobility, $d$ is the thickness of thin film, and $\theta$ is the ratio of the total density of free electrons to the trapped electrons.

$$
J_{\text {Schotky }}=A T^{2} \exp -\left[\frac{\varphi_{b}}{k_{\mathrm{B}} T}-\frac{e}{k_{\mathrm{B}} T}\left(\frac{e E}{4 \Pi \varepsilon_{0} K}\right)^{1 / 2}\right]
$$

Where $A$ is constant, $T$ is absolute temperature, $\varphi_{\mathrm{b}}$ is the voltage barrier, $k_{\mathrm{B}}$ is the Boltzmann constant, $e$ is the electron charge, $\varepsilon_{0}$ is the permittivity of free space and $K$ is the optical dielectric. It is clearly according to Eqs. (1-2) that the $\ln (J)$ is proportional to $\ln (E)$ for Ohmic conduction and SCLC mechanism, whose slope (S) of $\ln (J)-\ln (E)$ is 1 or 2 , respectively. While the $\ln (J)$ is proportional to $E^{1 / 2}$ in Eq. (3), suggesting the interface-limited Schottky emission conduction mechanism.

The curves of $\ln (J)-\ln (E)$ for BFGax-BT ceramics in Fig. 2a follow a nearly linear behavior with $S=1.91$ at $x=0$, indicating a dominant SCLC mechanism. However, the curve of $x=0.02$ in Fig. $2 \mathrm{~b}$ can be well fitted by two straight lines: the $S=1.22$ at $E \leq 3 \mathrm{kV} \cdot \mathrm{cm}^{-1}$ corresponds to Ohmic conduction; The $S=2.43$ at E>3 $\mathrm{kV} \cdot \mathrm{cm}^{-1}$ indicates a dominant SCLC mechanism which results from the electrons injects into the insulator at high electric field [20,28-32]. As $x$ increases to 0.04, the $\ln (J)-\ln (E)$ plot in Fig. 2c shows a linear behavior with $S=1.12$, suggesting that the leakage mechanisms transform to a pure Ohmic conduction. When $0.06 \leq x \leq 0.1$ at $E \leq 8 \mathrm{kV} \cdot \mathrm{cm}^{-1}$, the $\ln (J)-\ln (E)$ plots in Fig. 2d-f show a nonlinear behavior, thus single Ohmic conduction and SCLC mechanism can be ruled out. In order to confirm the leakage mechanism in this region, the $\ln (J)-E^{1 / 2}$ curves for $0.06 \leq x \leq 0.1$ are plotted in Fig. $2 \mathrm{~g}$. It is seen that the curves show obvious linear characteristic, suggesting the Schottky emission mechanism dominates according to Eq. 3. The same conduction mechanism was reported in $\mathrm{Bi}_{0.9} \mathrm{Laa}_{0.1} \mathrm{FeO}_{3}$ at low applied electric field [31]. When $\mathrm{E}>8 \mathrm{kV} \cdot \mathrm{cm}^{-1}$, the $S$ of $0.06 \leq x \leq 0.1$ in Fig. 2d-f is $0.92,0.85$ and 1.04, respectively, which correspond to Ohmic conduction. The slopes for $\ln (J)-\ln (E)$ and $\ln (J)-E^{1 / 2}$ are plotted in Fig. 2h, which exhibit the leakage mechanism transformation. 


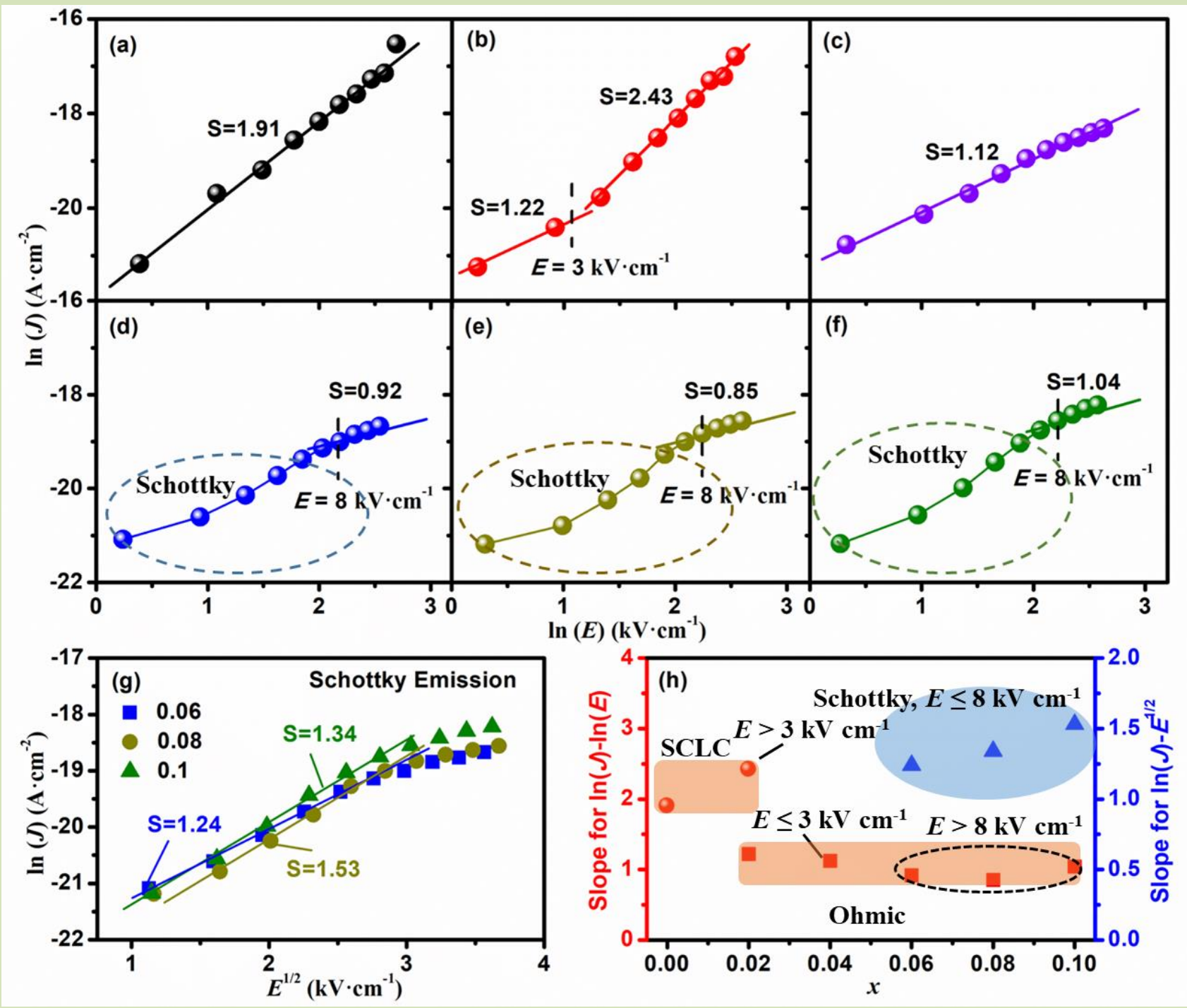

Fig. $2 \ln (J)-\ln (E)$ of $\mathrm{BFGa}_{x}$-BT ceramics: (a) $x=0$, (b) $x=0.02$, (c) $x=0.04$, (d) $x=0.06$, (e) $x=0.08$, (f) $x=0.1 ;(\mathrm{g}) \ln (J)-E^{1 / 2}$ for $\mathrm{BFGa}_{x}$-BT ceramics at $x=0.06,0.08$ and 0.1 ; (h) $x$-dependence of Slope.

It is well known that the $\mathrm{Bi}^{3+}$ volatilization and the valence change of $\mathrm{Fe}^{3+} \rightarrow \mathrm{Fe}^{2+}$ usually happened in BF ceramics, both of them could generate $\mathrm{V}_{\mathrm{O}}^{\bullet \bullet}$ corresponding to the $\mathrm{V}_{\mathrm{O} 1}^{\bullet \bullet}$ and $\mathrm{V}_{\mathrm{O} 2}^{\bullet \bullet}$ respectively, causing a high $J$, as shown in eqs. 4-5 [33-35].

$$
\begin{gathered}
2 \mathrm{BiFeO}_{3} \stackrel{\geq 830^{\circ} \mathrm{C}}{\longrightarrow} \mathrm{Bi}_{2} \mathrm{O}_{3} \uparrow+2 \mathrm{Fe}_{\mathrm{Fe}}^{\mathrm{x}}+3 \mathrm{O}_{\mathrm{O}}^{\mathrm{x}}+2 V_{\mathrm{Bi}}^{\prime \prime \prime}+3 V_{\mathrm{O} 1}^{\bullet \bullet} \\
2 \mathrm{Fe}_{\mathrm{Fe}}^{\mathrm{x}}+\mathrm{O}_{\mathrm{O}}^{\mathrm{x}} \rightarrow 2 \mathrm{Fe}_{\mathrm{Fe}}^{\prime}+V_{\mathrm{O} 2}^{\bullet \bullet}+\frac{1}{2} \mathrm{O}_{2} \uparrow
\end{gathered}
$$

In order to analysis the valence of the constituent elements, high resolution XPS spectral analyses were performed for BFGax-BT ceramics. The relative percent of $\mathrm{Fe}^{3+}$ and $\mathrm{O}_{\mathrm{I}}$ for $\mathrm{BFGa}_{x}-\mathrm{BT}$ ceramics as a function of $x$ are shown in Fig. 3a, along with the $\rho$ at $12 \mathrm{kV} \cdot \mathrm{cm}^{-1}$. The detailed information of Bi 4f, Ba 3d, Ti 2p Fe 
$2 \mathrm{p}$ and $\mathrm{O} 1 \mathrm{~s}$ can be seen in Fig. S1. It was found in Fig S1a that the $\mathrm{Bi}^{3+}$ volatilization is independent $x$, because all samples were calcined and sintered at the same temperature. The Fe $2 p$ peaks in Fig. S1d are broad and asymmetric, suggesting the coexistence of $\mathrm{Fe}^{3+}$ and $\mathrm{Fe}^{2+}$, which subdivided into $2 \mathrm{p}_{3 / 2}$ and $2 \mathrm{p}_{1 / 2}$ of $\mathrm{Fe}^{3+}$ and $\mathrm{Fe}^{2+}$. The fitting results of $\mathrm{Fe} 2 \mathrm{p}$ peaks for BFGax-BT ceramics $(0 \leq x \leq 0.08)$ by XPSPEAK41 soft are illustrated in Fig. S2a-e. After peak fitting, the relative percentages of $\mathrm{Fe}^{3+}\left(\mathrm{Fe}^{3+}(\%)\right)$ and $\mathrm{Fe}^{2+}\left(\mathrm{Fe}^{2+}(\%)\right)$ were calculated from peak areas using equation $\mathrm{Fe}^{3+}(\%)=(\mathrm{A} 1+\mathrm{A} 2) /(\mathrm{A} 1+\mathrm{A} 2+\mathrm{A} 3+\mathrm{A} 4)$, where $\mathrm{A} 1, \mathrm{~A} 2, \mathrm{~A} 3$ and A4 indicate the area of $\mathrm{Fe}^{3+} 2 \mathrm{p}_{3 / 2}, \mathrm{Fe}^{3+} 2 \mathrm{p}_{1 / 2}, \mathrm{Fe}^{2+} 2 \mathrm{p}_{3 / 2}$ and $\mathrm{Fe}^{2+} 2 \mathrm{p}_{1 / 2}$ near $710.9 \mathrm{eV}, 724.5 \mathrm{eV}, 710.0 \mathrm{eV}$ and $723.5 \mathrm{eV}$, respectively. The fitting results of $\mathrm{O} 1 \mathrm{~s}$ are shown in Fig. S3 by similar peak fitting and calculation process. The $\mathrm{Fe}^{3+}(\%)$ in Fig. 3a increases from $83 \%$ to $89 \%$ as $x$ increases from 0 to 0.06 , then decreases to $86 \%$ at $x=0.10$. The $\mathrm{O}_{\mathrm{I}}$ and $\rho$ show the same trend as $\mathrm{Fe}^{3+}$, which increase first and then decreases with $x$ increasing as shown in Fig. 3a. The maximum of $\mathrm{O}_{\mathrm{I}}$ and $\rho$ are achieved at $x=0.06$, which is $63 \%$ and $2.73 \times 10^{12} \Omega \cdot \mathrm{cm}^{-1}$. It is reasonable that Ga-doping will reduce $\mathrm{V}_{\mathrm{O} 1}^{\bullet \bullet}$ derived from the valence of Fe, leading to the different leakage mechanism, which is benefited for improving $\rho$.

Fig. 3b-c illustrates temperature dependence of $\tan \delta$ and $\varepsilon_{\mathrm{r}}$ for BFGax-BT ceramics measured at 100 $\mathrm{kHz}$ from RT to $600{ }^{\circ} \mathrm{C}$. The values of $\tan \delta$ for $x=0.02$ start to rise at $300{ }^{\circ} \mathrm{C}$, while the others remain relatively low until $350{ }^{\circ} \mathrm{C}$. The highest $\tan \delta$ at all testing temperatures is observed at $x=0.02$ due to the highest $\mathrm{V}_{\mathrm{O} 1}^{\bullet \bullet}$ content [36]. $\varepsilon_{\mathrm{r}}$ of all ceramics in Fig. 3c appears a peak corresponding to the Cure phase transition temperature. The $T_{\mathrm{C}}$ value firstly increases from $500{ }^{\circ} \mathrm{C}$ to $523{ }^{\circ} \mathrm{C}$ as $x$ increases from 0 to 0.04 , then decreases to $484{ }^{\circ} \mathrm{C}$ at $x=0.08$, indicating BFGa $x$-BT ceramics are promising piezoelectric materials for high-temperature application. Besides, a clearly relaxor-like behavior with wide phase transition temperature is detected at $x=0.1$. Combining with the XRD and Rietveld results in Fig. S4-S5 and Table S1, it is obvious the variation with $x$ of both $T_{\mathrm{C}}$ and $R$ phase fraction in Fig. 3d shows a good correction, which suggests the more $R$ phase, the higher $T_{\mathrm{C}}$. 


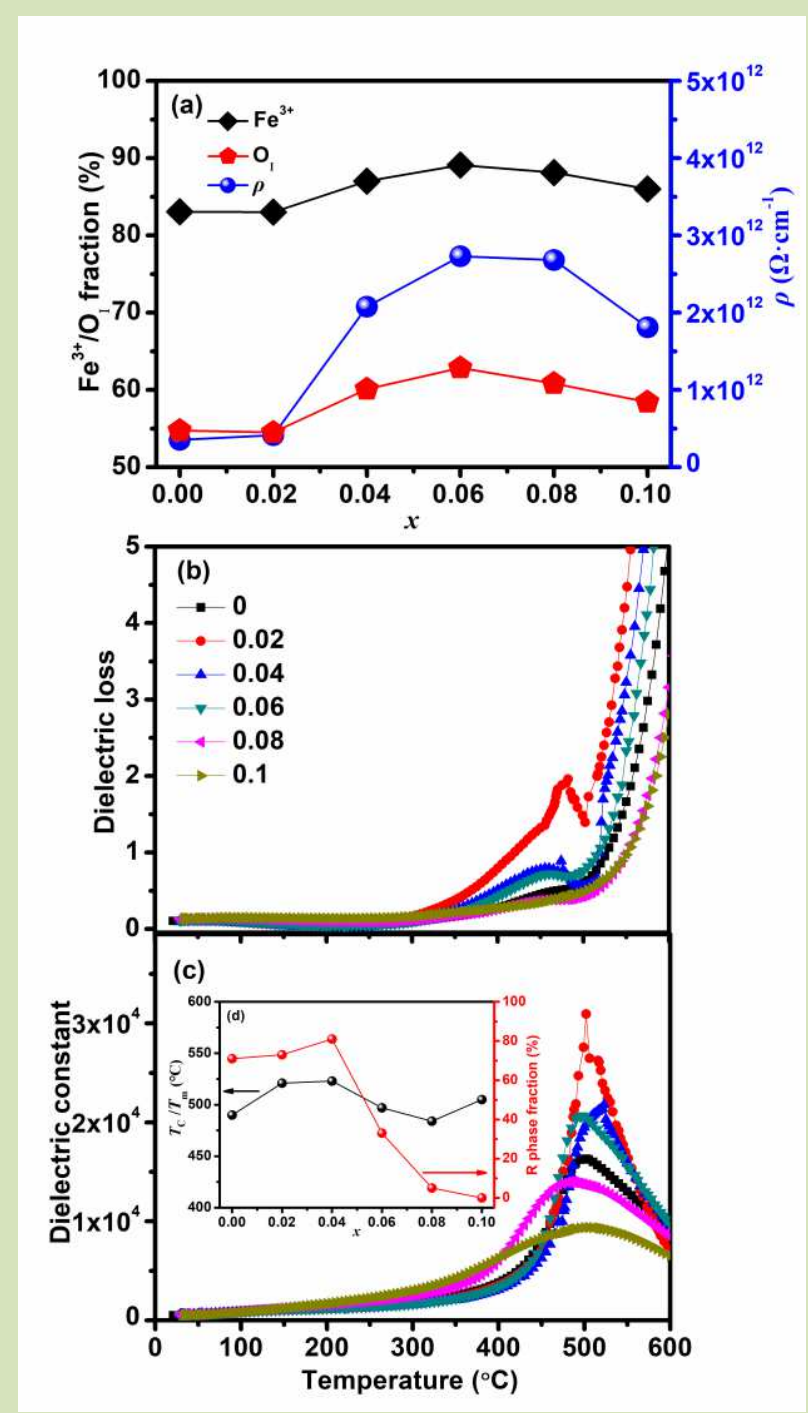

Fig. 3 (a) $x$-dependence of the relative percentage of $\mathrm{Fe}^{3+}$ and $\mathrm{O}_{\mathrm{I}}$ for $\mathrm{BFGa}_{x}$-BT ceramics, along with the $\rho$ at $12 \mathrm{kV} \cdot \mathrm{cm}^{-1}$; Temperature dependence of dielectric loss $(\tan \delta)(\mathrm{b})$ and dielectric constant $\left(\varepsilon_{\mathrm{r}}\right)(\mathrm{c})$ measured at $100 \mathrm{~Hz}$ for $\mathrm{BFGa}_{x}$-BT ceramics; (d) The $x$-dependence of Curie temperature $\left(T_{\mathrm{C}}\right)$ and $R$ phase fraction.

Fig. 4a-c shows $P-E$ loops at RT, bipolar $S$ - $E$ curves and unipolar $S-E$ curves measured at $50 \mathrm{kV} \cdot \mathrm{cm}^{-1}$ and $1 \mathrm{~Hz}$ for BFGax-BT ceramics, and the maximum polarization $\left(P_{\mathrm{m}}\right)$, remanent polarization $\left(P_{\mathrm{r}}\right)$, coercive field $\left(E_{\mathrm{C}}\right)$, bias electric field $\left(E_{\mathrm{i}}\right)$, positive strain $\left(S_{\mathrm{pos}}\right)$, negative strain $\left(S_{\text {neg }}\right)$, unipolar strain $\left(S_{\text {uni }}\right)$ and $\Delta P^{2}$ (the square of polarization difference, $P_{\mathrm{m}}^{2}-P_{\mathrm{r}}^{2}$ ) as a function of $x$ are summarized in Fig. 4d-f. All BFGax-BT ceramics exhibit saturated $P-E$ loops and butterfly $S$ - $E$ curves. As $x$ increasing, the $E_{\mathrm{i}}$ in Fig. $4 \mathrm{~d}$ increases firstly and then decreases. The maximum $E_{\mathrm{i}}$ is shown at $x=0.02$, indicating the existence of lots of defect-dipole, which results in the largest $P_{\mathrm{m}}=28.7 \mu \mathrm{C} \cdot \mathrm{cm}^{-2}$ and $P_{\mathrm{r}}=23.4 \mu \mathrm{C} \cdot \mathrm{cm}^{-2}$ because of the free point defects will be oriented under electric field . As $x \geq 0.8$, the structure is far from the appreciate phase fraction, 
which causes the decreased $P_{\mathrm{r}}$ and $P_{\mathrm{m}}$. Fig. $4 \mathrm{e}$ shows the $x$-dependence of $S_{\text {pos }}$ and $S_{\text {neg }}$ for BFGax-BT ceramics. $S_{\text {pos }}$ is a sum of intrinsic piezoelectric lattice strain and extrinsic reversible domain switching strain, while $S_{\text {neg }}$ involves the non- $180^{\circ}$ domain reorientation [38-39]. The increased $S_{\text {pos }}=0.14 \%$ and $S_{\text {neg }}=-0.06 \%$ at $x=0.08$ caused by the increased $P C$ phase results in the raise of distortion, which is consistent with the change of phase fraction. However, the structure of BFGax-BT ceramics turns to single phase fraction at $x=0.10$, which lead to the decrease of $S_{\text {pos }}$ and $S_{\text {neg. }}$ It is reported that the relationship between field-induced strain $(S)$ and the polarization $(P)$ usually written as $S=Q \Delta P^{2}$, where $Q$ represents the electrostrictive coefficient [40-42]. The $x$-dependence of $S_{\text {uni }}$ and $\Delta P^{2}$ are contrasted in Fig. 4f, exhibiting exactly the same traces that the maximum value $\Delta P^{2}=347 \mu \mathrm{C}^{2} \cdot \mathrm{cm}^{-4}$ and $S_{\text {uni }}=0.14 \%$ are achieved at $x=0.08$. Thus, the unipolar strain behavior in this work is attributed to the constant values of $\Delta P^{2}$.
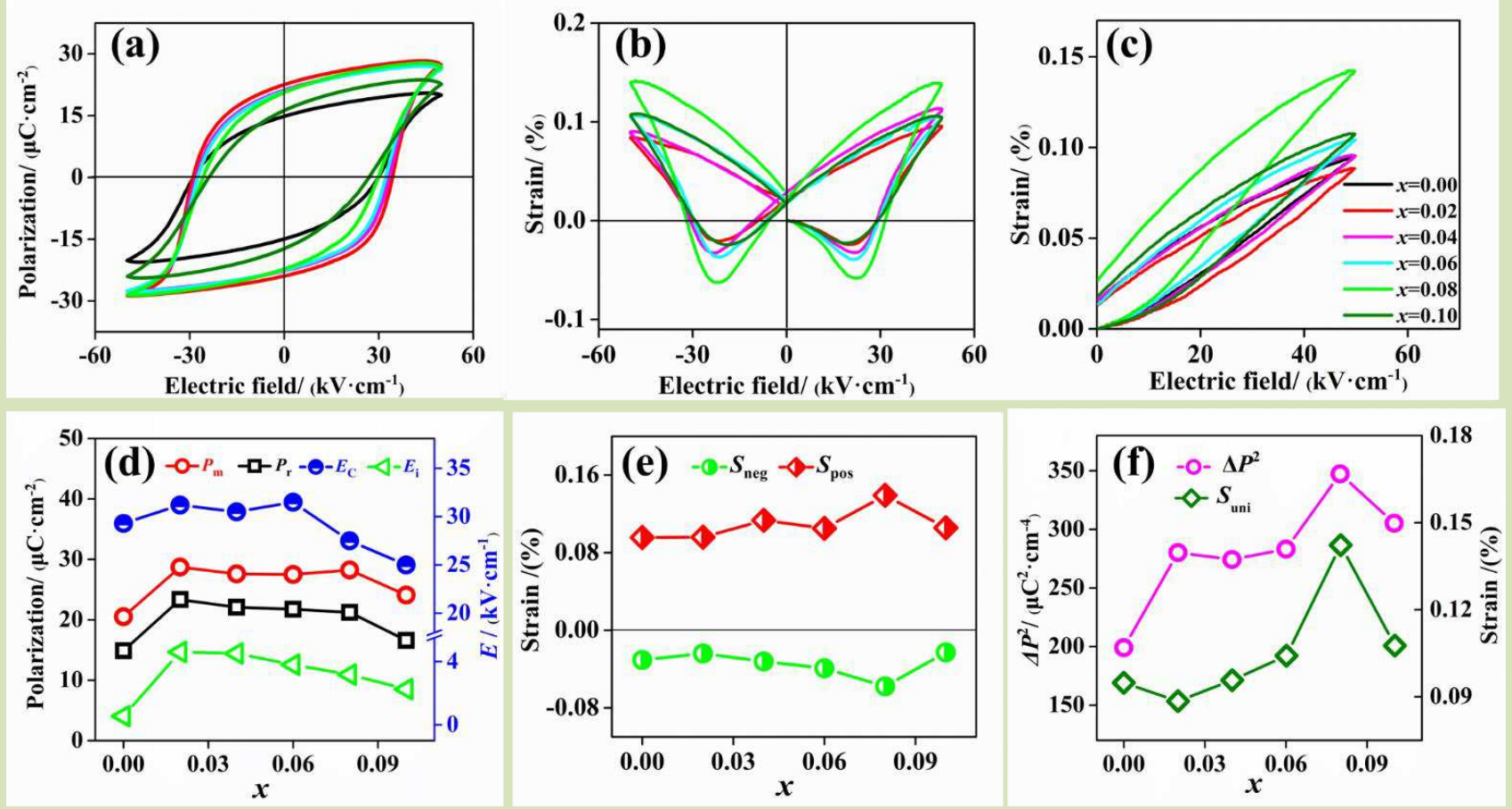

Fig. 4 (a) Bipolar $P$ - $E$ hysteresis loops, (b) bipolar $S$ - $E$ loops, and (c) unipolar $S$ - $E$ loops for BFGax-BT ceramics; $P_{\mathrm{m}}, P_{\mathrm{r}}, E_{\mathrm{C}}$ and $E_{\mathrm{i}}(\mathrm{d}), S_{\mathrm{pos}}$ and $S_{\text {neg }}(\mathrm{e}), \Delta P^{2}$ and $S_{\text {uni }}(\mathrm{f})$ as a function of $x$.

Fig. 5 illustrates the $x$-dependence of $d_{33}, k_{\mathrm{p}}$ and $Q_{\mathrm{m}}$ for BFGax-BT ceramics. The values of $d_{33}$ and $k_{\mathrm{p}}$ firstly increase and then decrease as $x$ increases. $Q_{\mathrm{m}}$ has little variation between 25 and 29 with $x$ apart from the trend of $d_{33}$ and $k_{\mathrm{p}}$. The highest $d_{33}=174 \mathrm{pC} \cdot \mathrm{N}^{-1}$ and $k_{\mathrm{p}}=29 \%$ are achieved at $x=0.06$, along with a high 
$T_{\mathrm{C}}=497{ }^{\circ} \mathrm{C}$ because of the synergistic effect of appropriate MPB, high relative density and low $J$, as shown in Fig. S4-S6 and Fig. 1. Although they are inferior to piezoelectric properties $d_{33}=402 \mathrm{pC} \cdot \mathrm{N}^{-1}, T_{\mathrm{C}}=454{ }^{\circ} \mathrm{C}$ obtained in the water quenched $\mathrm{BF}-33 \mathrm{BT}-3 \mathrm{BiGaO}_{3}$ ceramic, $d_{33}$ and $k_{\mathrm{p}}$ are obviously superior to the value reported in BFGax-BT ceramics prepared by solid solution method.

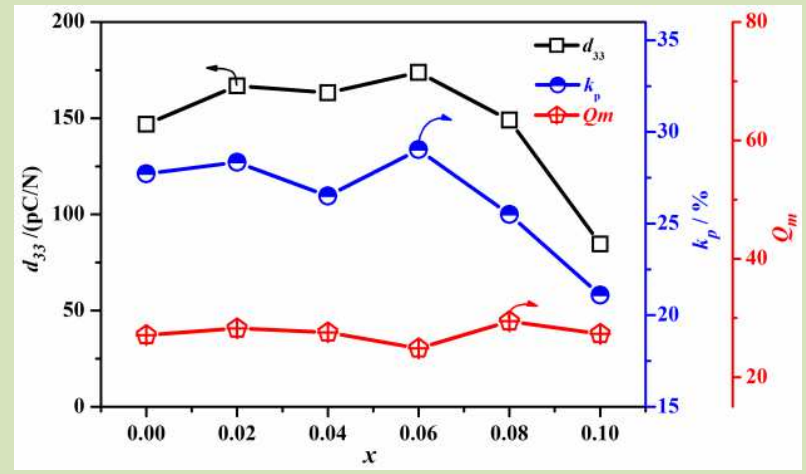

Fig. 5 Piezoelectric coefficient $\left(d_{33}\right)$, electromechanical coupling factors $\left(k_{\mathrm{p}}\right), Q_{\mathrm{m}}$ as a function of $x$ for $\mathrm{BFGa}_{x}$-BT ceramics.

\section{Conclusions}

$0.7 \mathrm{BiFe}_{(1-x)} \mathrm{Ga}_{x} \mathrm{O}_{3}-0.3 \mathrm{BaTiO}_{3}(\mathrm{BFGa}-\mathrm{BT}, 0 \leq x \leq 0.10)$ ceramics were prepared by the conventional solid state reaction method. The valence of $\mathrm{Fe}^{3+}$ and $\mathrm{V}_{\mathrm{O} 1}^{\bullet}$ were suppressed by Ga-doping, resulting in the increased $\rho$ and decreased $J$. The highest $\mathrm{Fe}^{3+}(89 \%)$ content with high $\rho=2.73 \times 10^{12} \Omega \cdot \mathrm{cm}^{-1}$ and low $J$ $=7.78 \times 10^{-9} \mathrm{~A} \cdot \mathrm{cm}^{-2}$ under $12 \mathrm{kV} \cdot \mathrm{cm}^{-1}$ were obtained at $x=0.06$. The $J-E$ curves reveal the different type of conduction process in BFGax-BT ceramics. As $x$ increases, the leakage conduction mechanism changes from SCLC mechanism at $x=0$ into Ohmic conduction at $x=0.04$. Both of the Schottky emission and Ohmic conduction are existed in $0.06 \leq x \leq 0.10$. Due to the suitable MPB, high relative density and low $J$, the highest piezoelectric properties $d_{33}=174 \mathrm{pC} \cdot \mathrm{N}^{-1}$ and $k_{\mathrm{p}}=29 \%$ with a high $T_{\mathrm{C}}=497{ }^{\circ} \mathrm{C}$ were achieved at $x=0.06$, indicating the BFGax-BT system has a promising prospect in high temperature piezoelectric devices.

\section{Conflicts of interest}

There are no conflicts of interest to declare.

\section{Acknowledgments}


This work was supported by National Natural Science Foundation of China (grant No. 52072028 and 52032007).

\section{Electronic Supplementary Material}

Supplementary material about XPS patterns, XRD patterns, Rietveld refined results of XRD patterns and SEM images for BFGax-BT ceramics is available in the online version of this article at https:// doi.org/10.1007/s40145-...

\section{References:}

[1] Zhang S, Li F, Jiang X, et al. Advantages and challenges of relaxor- $\mathrm{PbTiO}_{3}$ ferroelectric crystals for electroacoustic transducers - A review. Prog Mater Sci. 2015, 68:1-66.

[2] Catalan G, Scott J F. Physics and Applications of Bismuth Ferrite. Adv Mater. 2009, 21:2463-2485.

[3] Singh S K, Maruyama K, Ishiwara H. Reduced leakage current in La and Ni codoped $\mathrm{BiFeO}_{3}$ thin films. Appl Phys Lett. 2007, 91:112913.

[4] Palai R, Katiyar R S, Schmid H, et al. $\beta$ phase and $\gamma-\beta$ metal-insulator transition in multiferroic $\mathrm{BiFeO}_{3}$. Phys Rev B. 2008, 77:14110.

[5] JEON S, YOON B, KIM K, et al. Effects of core/shell volumetric ratio on the dielectric-temperature behavior of $\mathrm{BaTiO}_{3}$. J Adv Ceram. 2014, 3:76-82.

[6] WANG X, CHEN I, DENG X, et al. New Progress In Development Of ferroelectric and piezoelectric nanoceramics. $J$ Adv Ceram. 2015, 4:1-21.

[7] WANG K, LI J. (K, Na) $\mathrm{NbO}_{3}$-based lead-free piezoceramics: Phase transition, sintering and property enhancement. J Adv Ceram. 2012, 1:24-37.

[8] Li J, Wang K, Zhu F, et al. (K,Na) $\mathrm{NbO}_{3}$-Based Lead-Free Piezoceramics: Fundamental Aspects, Processing Technologies, and Remaining Challenges. J Am Ceram Soc. 2013, 96:3677-3696.

[9] Liu Q, Zhang Y, Gao J, et al. Practical high-performance lead-free piezoelectrics: structural flexibility beyond utilizing multiphase coexistence. Natl Sci Rev. 2020, 7:355-365.

[10] Chu B, Chen D, Li G, et al. Electrical properties of $\mathrm{Na}_{1 / 2} \mathrm{Bi}_{1 / 2} \mathrm{TiO}_{3}-\mathrm{BaTiO}_{3}$ ceramics. J Eur Ceram Soc. 2002, 22:2115-2121.

[11] Yin J, Liu G, Zhao C, et al. Perovskite $\mathrm{Na}_{0.5} \mathrm{Bi}_{0.5} \mathrm{TiO}_{3}$ : a potential family of peculiar lead-free electrostrictors. J Mater Chem a. 2019, 7:13658-13670.

[12] Kumar M M, Srinivas A, Suryanarayana S V. Structure property relations in $\mathrm{BiFeO}_{3} / \mathrm{BaTiO}_{3}$ solid solutions. J Appl Phys. 2000, 87:855.

[13] Kim S, Khanal G P, Nam H, et al. Structural and electrical characteristics of potential candidate lead-free $\mathrm{BiFeO}_{3}-\mathrm{BaTiO}_{3}$ piezoelectric ceramics. J Appl Phys. 2017, 122:164105.

[14] Leontsev S O, Eitel R E. Dielectric and Piezoelectric Properties in Mn-Modified (1-x)BiFeO ${ }_{3}$ -xBaTiO3 Ceramics. J Am Ceram Soc. 2009, 92:2957-2961.

[15] Cheng S, Zhang Bp, Zhao L, et al. Enhanced insulating and piezoelectric properties of $0.7 \mathrm{BiFeO}_{3}-0.3 \mathrm{BaTiO}_{3}$ lead-free ceramics by optimizing calcination temperature: analysis of $\mathrm{Bi}^{3+}$ volatilization and phase structures. J Mater Chem C. 2018, 6:3982-3989.

[16] Rojac T, Bencan A, Malic B, et al. $\mathrm{BiFeO}_{3}$ Ceramics: Processing, Electrical, and Electromechanical Properties. J Am Ceram Soc. 2014, 97:1993-2011. 
[17] Selbach S M, Einarsrud M, Grande T. On the Thermodynamic Stability of $\mathrm{BiFeO}_{3}$. Chem Mater. 2009, 21:169-173.

[18] Wang D, Wang G, Murakami S, et al. $\mathrm{BiFeO}_{3}-\mathrm{BaTiO}_{3}$ : A new generation of lead-free electroceramics. Journal of Advanced Dielectrics. 2019, 08:1830004.

[19] Qi X, Dho J, Tomov R, et al. Greatly reduced leakage current and conduction mechanism in aliovalent-ion-doped $\mathrm{BiFeO}_{3}$. Appl Phys Lett. 2005, 86:62903.

[20] Qin Y, Yang J, Xiong P, et al. The effects of quenching on electrical properties, and leakage behaviors of $0.67 \mathrm{BiFeO}_{3}-0.33 \mathrm{BaTiO}_{3}$ solid solutions. Journal of Materials Science: Materials in Electronics. 2018, 29:7311-7317.

[21] Lee M H, Kim D J, Park J S, et al. High-Performance Lead-Free Piezoceramics with High Curie Temperatures. Adv Mater. 2015, 27:6976-6982.

[22] Cheng S, Zhao L, Zhang B, et al. Lead-free $0.7 \mathrm{BiFeO}_{3}-0.3 \mathrm{BaTiO}_{3}$ high-temperature piezoelectric ceramics: Nano- $\mathrm{BaTiO}_{3}$ raw powder leading to a distinct reaction path and enhanced electrical properties. Ceram Int. 2019, 45:10438-10447.

[23] Peng $X$, Zhu L, Zhang B, et al. Enhanced ferroelectric and piezoelectric properties of $\left(\mathrm{Bi}_{1-\mathrm{x}} \mathrm{La}_{\mathrm{x}}\right)$ $\mathrm{FeO}_{3}-\mathrm{BaTiO}_{3}$ ceramics near Morphotropic phase boundary. J Electroceram. 2019, 42:67-73.

[24] Chen J, Zhang B, Zhu L, et al. Enhanced insulation resistance and electrical properties of BiFe $\mathrm{1}_{-\mathrm{x}}\left(\mathrm{Zn}_{0.5}\right.$ $\left.\mathrm{Ti}_{0.5}\right)_{\times} \mathrm{O}_{3}-\mathrm{BaTiO}_{3}$ lead-free piezoceramics. Ceram Int. 2018, 44:8409-8416.

[25] Sun Y, Yang H, Guan S, et al. Strong piezoelectricity of $\mathrm{Li}_{2} \mathrm{CO}_{3}$-doped $\mathrm{BiFeO}_{3}-\mathrm{BaTiO}_{3}-\mathrm{Bi}_{(}\left(\mathrm{Zn}_{0.5} \mathrm{Ti}_{0.5}\right)$ $\mathrm{O}_{3}$ lead-free piezoelectric ceramics with high Curie temperature and high temperature stability. $J$ Alloy Compd. 2020, 819:153058.

[26] Akram F, Malik R A, Khan S A, et al. Electromechanical properties of ternary $\mathrm{BiFeO}_{3}-0.35 \mathrm{BaTiO}_{3}-\mathrm{BiGaO}_{3}$ piezoelectric ceramics. J Electroceram. 2018, 41:93-98.

[27] Zhou Q, Zhou C, Yang H, et al. Piezoelectric and ferroelectric properties of Ga modified $\mathrm{BiFeO}_{3}-\mathrm{BaTiO}_{3}$ lead-free ceramics with high Curie temperature. Journal of Materials Science: Materials in Electronics. 2014, 25:196-201.

[28] Pabst G W, Martin L W, Chu Y, et al. Leakage mechanisms in $\mathrm{BiFeO}_{3}$ thin films. Appl Phys Lett. 2007, 90:72902.

[29] Auromun K, Choudhary R N P. Structural, dielectric, and electrical characteristics of selenium-modified $\mathrm{BiFeO}_{3}-(\mathrm{BaSr}) \mathrm{TiO}_{3}$ ceramics. Journal of Materials Science: Materials in Electronics. 2020, 31:13415-13433.

[30] Sharma S, Cruz M P, Siqueiros J M, et al. Investigation of electrical, magneto-dielectric and transport properties of multiferroic $(1-\mathrm{x}) \mathrm{BiFeO}_{3}-(\mathrm{x}) \mathrm{BaSr}_{0.7} \mathrm{Ti}_{0.3} \mathrm{O}_{3}$ solid solutions. Journal of Materials Science: Materials in Electronics. 2019, 30:7447-7459.

[31] Cai W, Gao R, Fu C, et al. Microstructure, enhanced electric and magnetic properties of $\mathrm{Bi}_{0.9} \mathrm{La}_{0.1} \mathrm{FeO}_{3}$ ceramics prepared by microwave sintering. J Alloy Compd. 2019, 774:61-68.

[32] Wang C, Takahashi M, Fujino $\mathrm{H}$, et al. Leakage current of multiferroic $\left(\mathrm{Bi}_{0.6} \mathrm{~Tb}_{0.3} \mathrm{La}_{0.1}\right) \mathrm{FeO}_{3}$ thin films grown at various oxygen pressures by pulsed laser deposition and annealing effect. J Appl Phys. 2006, 99:54104.

[33] Calisir I, Hall D A. Chemical heterogeneity and approaches to its control in $\mathrm{BiFeO}_{3}-\mathrm{BaTiO}_{3}$ lead-free ferroelectrics. J Mater Chem C. 2018, 6:134-146.

[34] Xun B, Tang Y, Chen J, et al. Enhanced resistance in $\mathrm{Bi}\left(\mathrm{Fe}_{1-\mathrm{x}} \mathrm{Sc}_{\mathrm{x}}\right) \mathrm{O}_{3}-0.3 \mathrm{BaTiO}_{3}$ lead-free piezoelectric ceramics: Facile analysis and reduction of oxygen vacancy. J Eur Ceram Soc. 2019, 39:4085-4095.

[35] Yuan G L, Or S W, Wang Y P, et al. Preparation and multi-properties of insulated single-phase $\mathrm{BiFeO}_{3}$ ceramics. Solid State Commun. 2006, 138:76-81.

[36] Zhang H, Jo W, Wang K, et al. Compositional dependence of dielectric and ferroelectric properties in $\mathrm{BiFeO}_{3}-\mathrm{BaTiO}_{3}$ solid solutions. Ceram Int. 2014, 40:4759-4765. 
[37] Zheng T, Wu J. Defect dynamics me diate d unusual field-cycling behavior in bismuth ferrite-based ceramics. Scripta Mater. 2020, 187:418-423.

[38] Wang G, Fan Z, Murakami S, et al. Origin of the large electrostrain in $\mathrm{BiFeO}_{3}-\mathrm{BaTiO}_{3}$ based lead-free ceramics. J Mater Chem a. 2019, C9T-C7904T.

[39] Wang L, Liang R, Zhou Z, et al. High electrostrain with high Curie temperature in $\mathrm{BiFeO}_{3}-\mathrm{BaTiO}_{3}$-based ceramics. Scripta Mater. 2019, 164:62-65.

[40] Wang K, Yao F, Jo W, et al. Temperature-Insensitive (K,Na) $\mathrm{NbO}_{3}$-Based Lead-Free Piezoactuator Ceramics. Adv Funct Mater. 2013, 23:4079-4086.

[41] Lv J, Gao W, Li J, et al. Large strain and strain memory effect in bismuth ferrite lead-free ceramics. Journal of materials chemistry. C, Materials for optical and electronic devices. 2017, 5:9528-9533.

[42] UCHINO K, NOMURA S, Cross L E, et al. Review Electrostrictive effect in perovskites and its transducer applications. J Mater Sci. 1981, 16:569-578. 
Figures

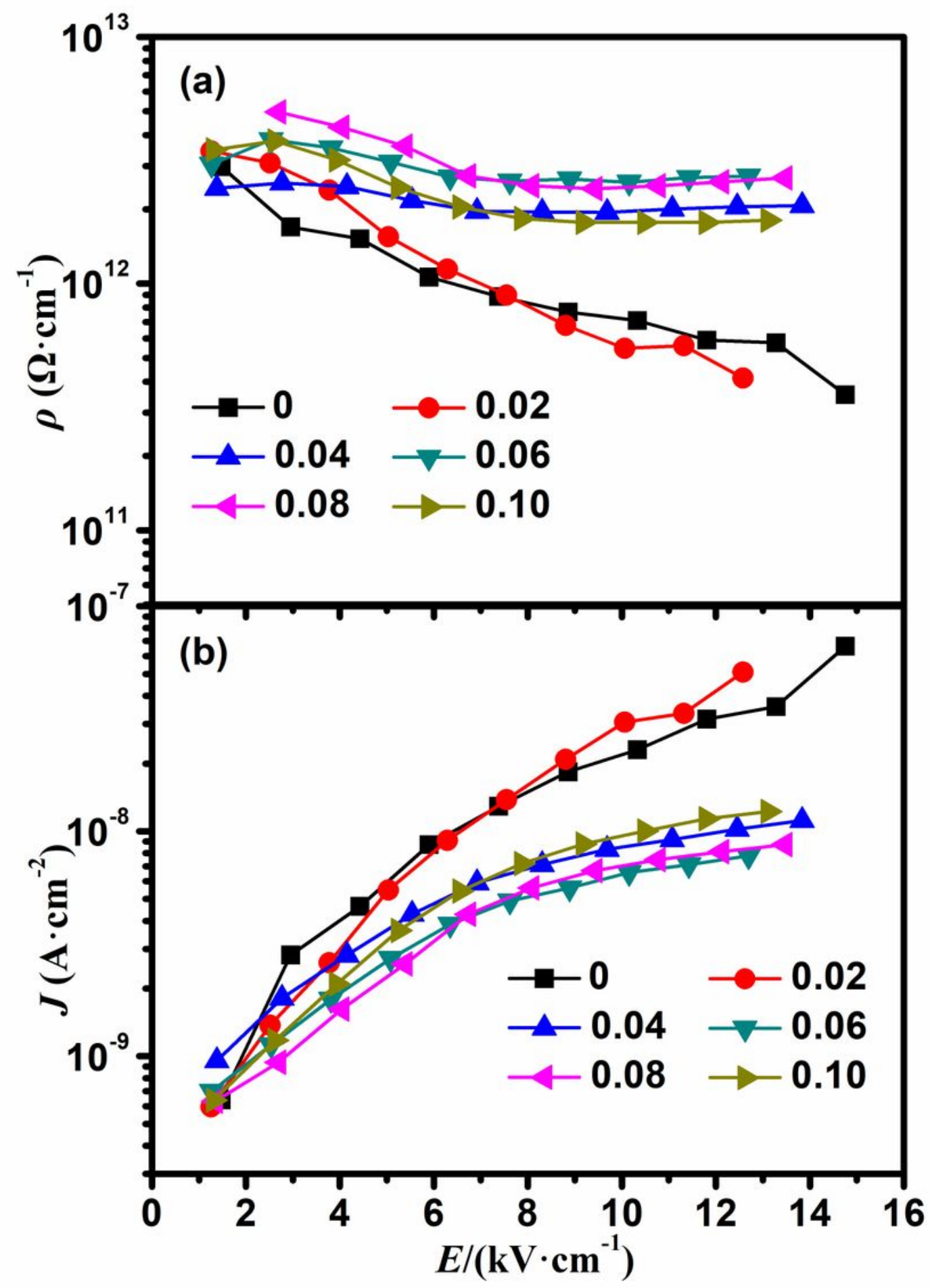

Figure 1

$\rho-E(a)$ and J-E (b) of BFGax-BT ceramics measured at room temperature. 

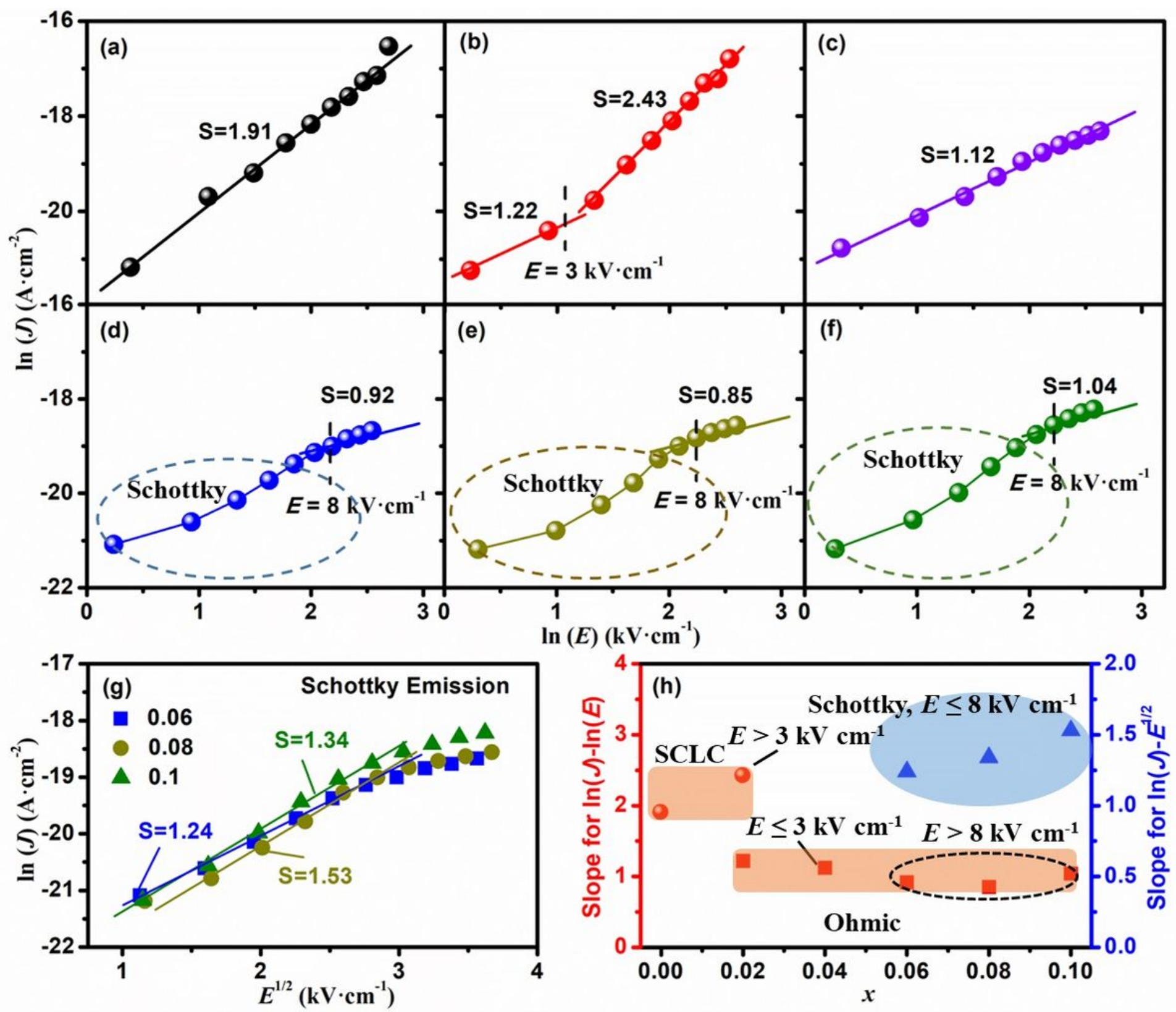

Figure 2

$\ln (J)-\ln (E)$ of BFGax-BT ceramics: (a) $x=0$, (b) $x=0.02$, (c) $x=0.04$, (d) $x=0.06$, (e) $x=0.08$, (f) $x=0.1 ;$ (g) $\ln (J)$ $\mathrm{E} 1 / 2$ for BFGax-BT ceramics at $\mathrm{x}=0.06,0.08$ and 0.1 ; (h) $\mathrm{x}$-dependence of Slope. 

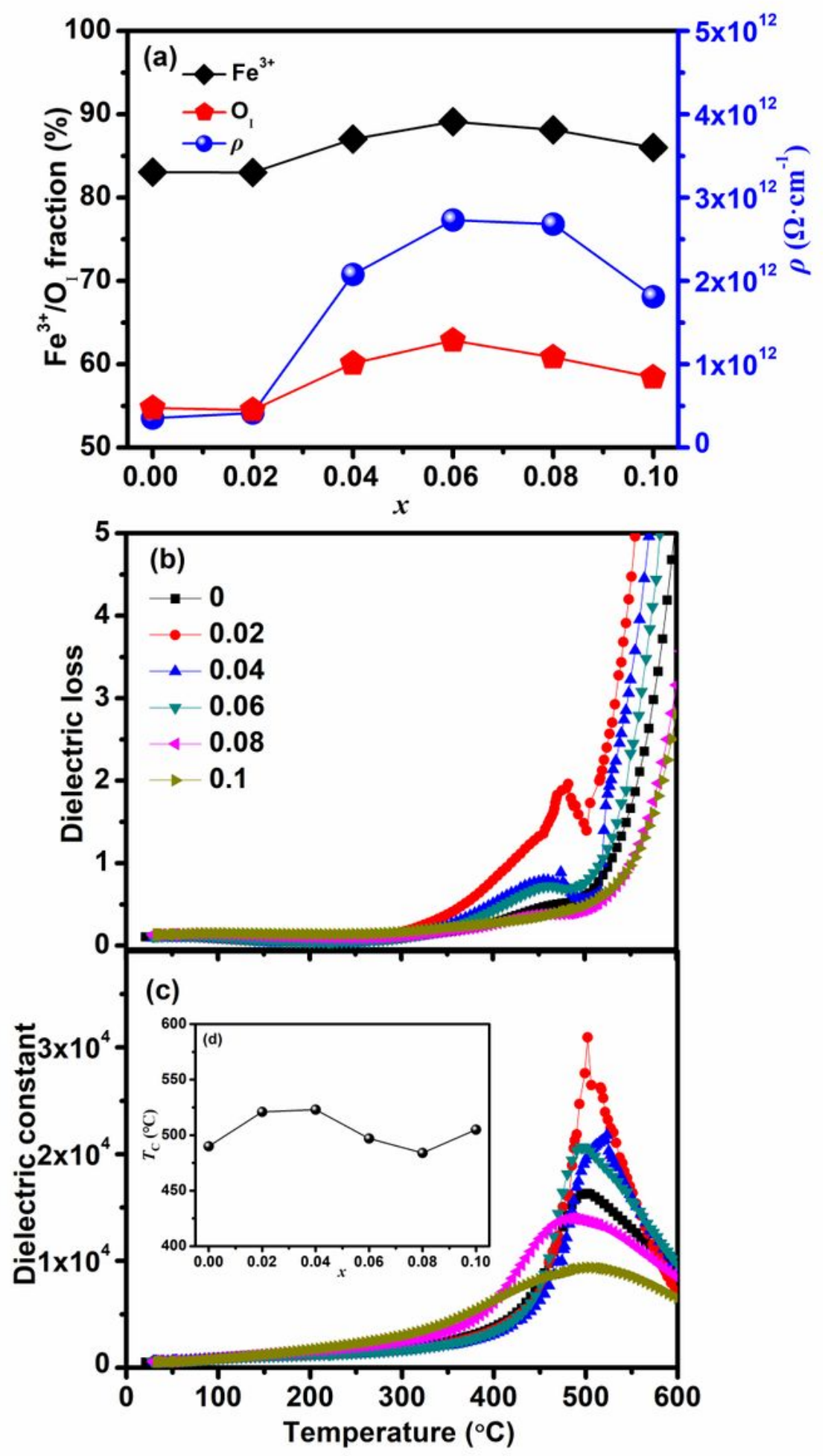

Figure 3

(a) $x$-dependence of the relative percentage of Fe3+ and $\mathrm{O} \otimes$ for BFGax-BT ceramics, along with the $\rho$ at 12

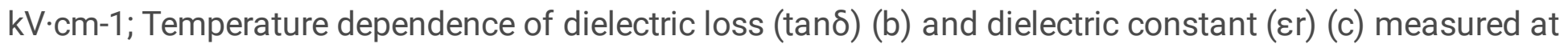
$100 \mathrm{~Hz}$ for BFGax-BT ceramics; (d) The $\mathrm{x}$-dependence of Curie temperature (TC) and R phase fraction. 

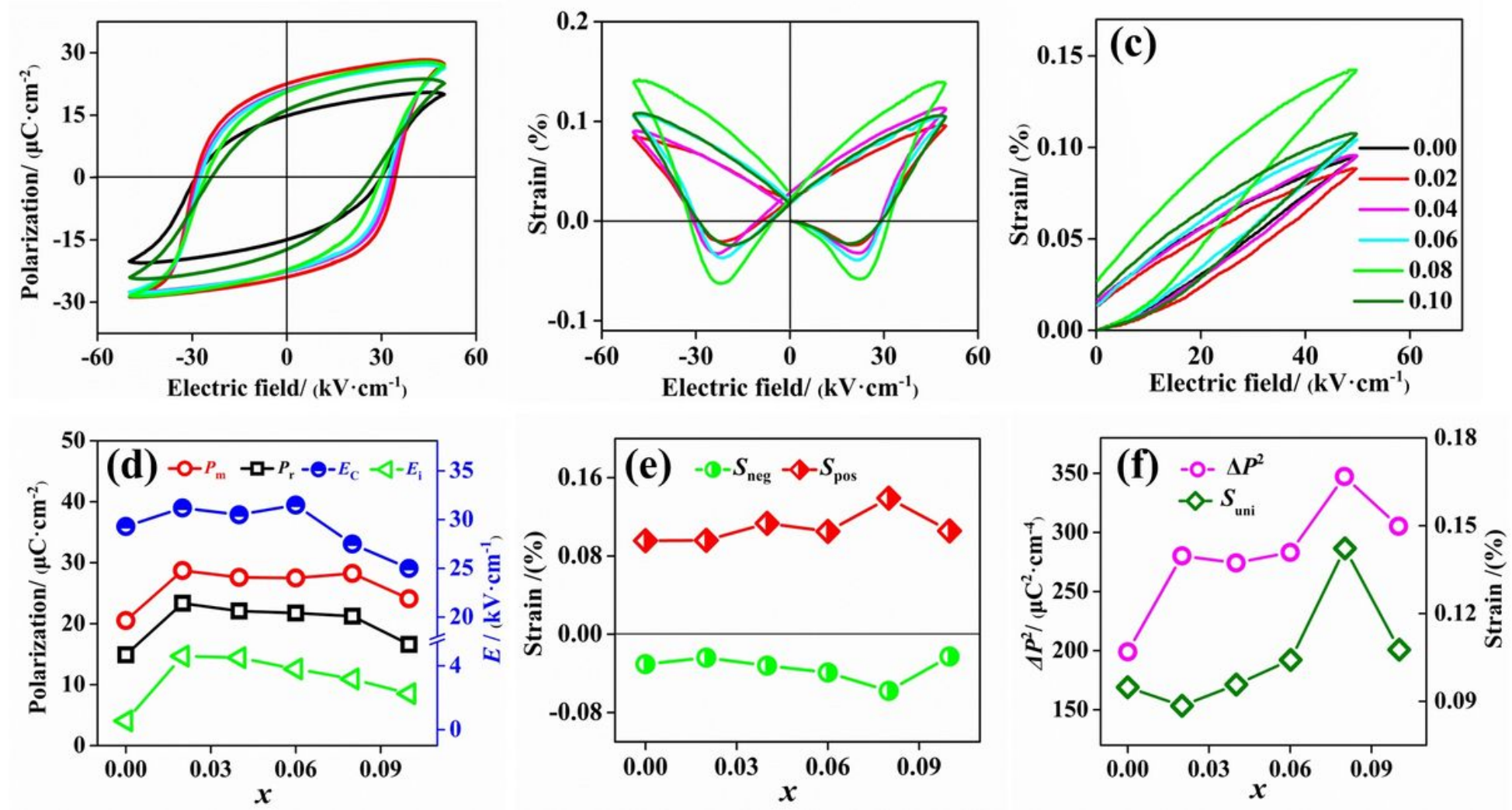

Figure 4

(a) Bipolar P-E hysteresis loops, (b) bipolar S-E loops, and (c) unipolar S-E loops for BFGax-BT ceramics; Pm, Pr, EC and Ei (d), Spos and Sneg (e), $\triangle \mathrm{P} 2$ and Suni (f) as a function of $\mathrm{X}$.

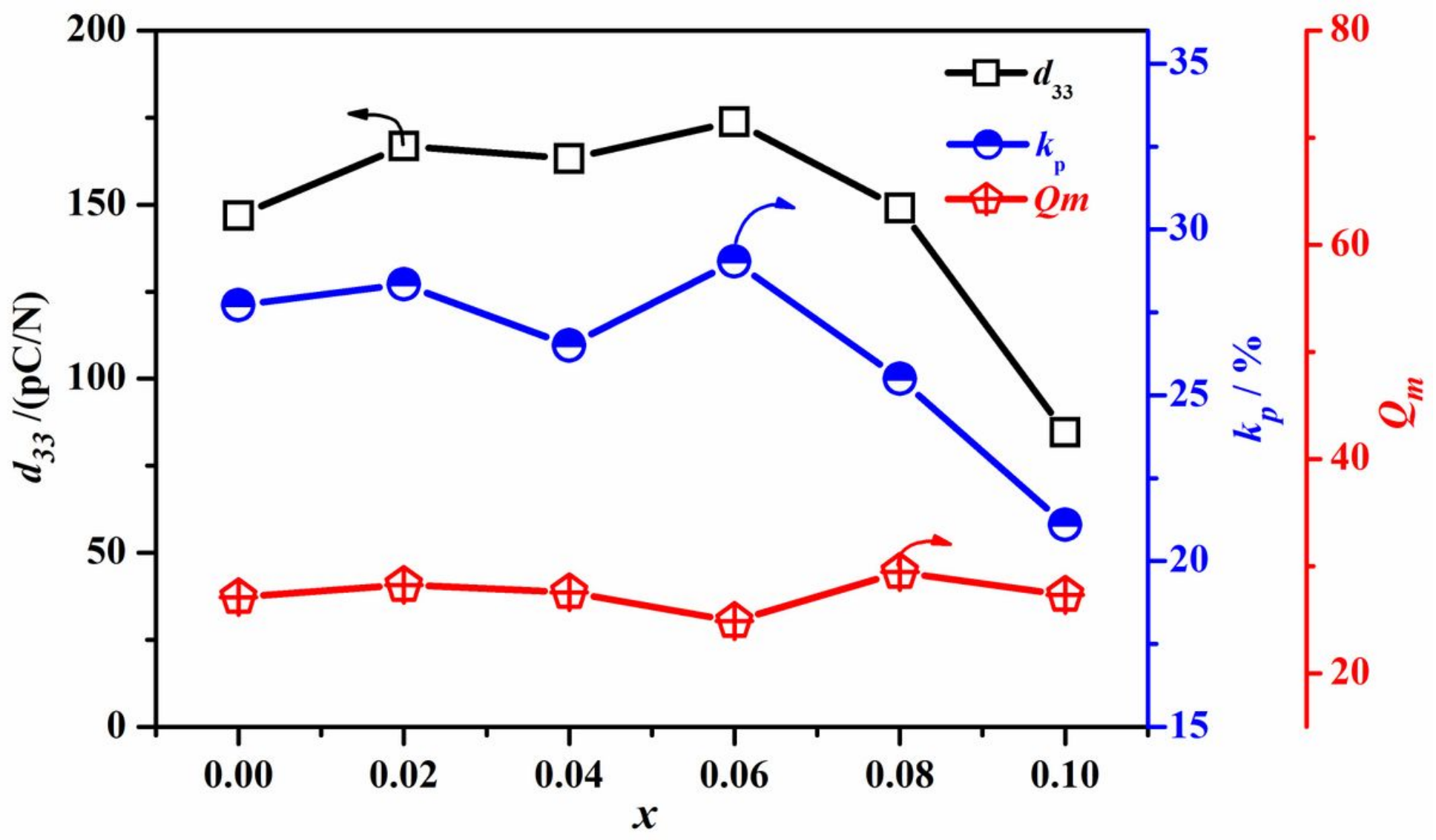


Figure 5

Piezoelectric coefficient (d33), electromechanical coupling factors (kp), Qm as a function of $x$ for BFGaxBT ceramics.

\section{Supplementary Files}

This is a list of supplementary files associated with this preprint. Click to download.

- pxyJadvceramsupplementarymaterials20201022.doc 